УДК 339.5-005.2

\title{
МИРОВАЯ ЭКОНОМИКА СКВОЗЬ ГЕНДЕРНУЮ ПРИЗМУ
}

\author{
С.В. ПАВЛОВСКАЯ
}

канд. экон. наук, доцент кафедры мировой экономики Белорусского государственного экономического университета, г. Минск

\section{Ю.А. ШАВРУК}

канд. экон. наук, доцент кафедры международного бизнеса Белорусского государственного экономического университета, г. Минск

\section{Аннотация}

В статье изложены основные теоретические подходы к пониманию сущьности категории «гендер», рассматривается влияние гендерного неравенства на экономическое развитие в разных странах и в Республике Беларусь.

Ключевые слова: гендерный подход, гендер, гендерное неравенство.

\section{Abstract}

The article describes the main theoretical approaches to the definition of "gender" category, examines the impact of gender inequality on economic development in different countries and in the Republic of Belarus.

Key words: gender approach, gender, gender inequality.

\section{ВВЕДЕНИЕ}

Влияние гендерного неравенства на экономическое развитие стран является предметом изучения и острых дискуссий на национальном и международном уровнях. Особенно остро проблема гендерного неравенства стоит последние 30 лет, т.к. было доказано, что преодоление гендерного разрыва положительно влияет на экономический рост [1].

Глобализация способствовала увеличению трансграничных потоков товаров и услуг, капитала, технологий и информации. Предполагалось, что в этот период снижение экономических, географических и культурных барьеров, приведет к более высокому уровню производительности и расширению возможностей для трудовых ресурсов. Экономическая политика государств часто формировалась под влиянием предположения, что рыночные силы будет автоматически обеспечивать эти результаты. 
В реальности оказалось, что существует разрыв между экономическим ростом и социальным развитием: неравенство доходов, социальное неравенство и социальное расслоение увеличились даже в тех странах, в которых был зафиксирован высокий уровень экономического роста и увеличение темпов роста торговли. Стало очевидным, что экономическая политика по-разному влияет на различные слои населения, и прежнее предположение о том, что экономическая политика «гендерна нейтральна» неверно. Также стало понятно, что экономическая политика государства может играть важнейшую роль в сокращении гендерного неравенства.

\section{РЕЗУЛЬТАТЫ И ИХ ОБСУЖДЕНИЕ}

Научное исследование, проведенное ЮНКТАД, показало, что различные роли мужчины и женщины в обществе и экономике оказывают влияние не только на показатели экономики страны, но и на гендерную способность воспользоваться возможностями, возникающими благодаря расширению торговли [2, с. 2].

Изучение гендерной проблематики способствует более глубокому пониманию динамики показателей торговли и привносит новое понимание в формирование торговой политики государства. Гендерный подход играет важную роль, в результате чего на первый план выходит неравенство - в том числе неравенство доходов, а также горизонтальные различия, проявляющиеся в расовой / этнической / кастовой принадлежности, что обычно упускается при анализе результатов торговой политики. Глубоко вникая в социальные нормы, гендерный подход объединяет социальные и культурные факторы в экономическом анализе. Это, в свою очередь, стимулирует переход от формальной модели экономической системы к реальной экономической действительности. В целом, гендерный подход в перспективе обеспечивает основу для переосмысления основ экономической и торговой политики и, в частности, увеличивает их социальную значимость.

По определению ООН сущность «гендерного подхода» заключается в том, что это в первую очередь: «... процесс оценки любого планируемого мероприятия с точки зрения его воздействия на женщин и мужчин, в том числе законодательства, стратегий и программ во всех областях и на всех уровнях. Настоящая стратегия основывается на том, чтобы интересы и опыт женщин, равно как и мужчин, стали неотъемлемым критерием при разработке общей концепции, при осуществлении, мониторинге и оценке общих направлений деятельности и программ во всех политических, экономических и общественных сферах с тем, чтобы и женщины 
и мужчины могли получать равную выгоду, а неравенство никогда не укоренялось бы» [3, с. 8].

Для того чтобы анализировать влияние гендерного подхода на торговлю, необходимо дать так же определение гендеру. Так, Конференция по торговле и развитию Организации объединенных наций определяет гендер как «систему норм, которая приписывает определенные роли, характеристики и поведение для мужчин и женщин на основе их пола и общепринятого подчиненного статуса женщин в обществе» [2, с. 1] .

Организация женщин ООН определяет гендер как социальные черты и возможности связанные с полом и взаимоотношения между полами [4]. Гендер является неотъемлемой частью социо-культурной системы общества.

Дискриминация по половому признаку лишает женщин таких же экономических, социальных и политических возможностей, которыми располагают мужчины. Под термином «гендерное неравенство» подразумевается конкретное проявление дискриминации по половому признаку, которое создает неудобства для женщин (например, более низкую заработную плату за одинаковый труд), а под термином «гендерное равенство» - ситуации, где мужчины и женщины получают равные возможности (например, равную оплату за одинаковый труд).

Экономика должна рассматриваться как «гендерная структура», т.е. часть системы общественных отношений, в которые уже включен гендер [5]. Например, половая дискриминация в области рынка труда означает, что женщины могут получить доступ к ограниченному кругу профессий и заработная плата не соответствует их вкладу. Это является не только нарушением основного права на труд, но и не позволяет воспользоваться государству полной производственной мощностью рабочей силы. Доступ женщин к рабочим местам увеличивает их доходы, что сглаживает гендерное неравенство.

Рассматривая экономику как гендерную структуру, следует сделать акцент на неоплачиваемой работе по дому и уходу за членами семьи, что имеет жизненноважное значение для дальнейшего функционирования рыночно-ориентированной экономики. Специалисты по гендеру обращают внимание на тот факт, что товары и услуги, необходимые для достойного уровня жизни, производятся не только за счет рынка труда, но и посредством многочасового неоплачиваемого домашнего труда (приготовление пищи и уборка, уход за детьми, пожилыми людьми, больными и нетрудоспособными взрослыми) [4].

Этот неоплаченный труд, хоть и остается «невидимым», имеет жизненно важное значение для функционирования рыночноориентированной экономики. Поэтому необходимо расширить границы 
экономической системы, которая должна включать как рыночные, так и нерыночные направления деятельности [5]. Понимание взаимозависимости между нерыночной и рыночной деятельностью, а также гендерное разделение труда в них, является отправной точкой для любого гендерносенситивного экономического анализа.

Гендерные нормы определяют, что является мужской и женской работой, а это предполагает, что основной объем работы по дому входит в женскую работу. Это означает, что женщины (гораздо больше, чем мужчины) имеют двойное бремя участия как в оплачиваемой, так и в неоплачиваемой работе. Эта двойная роль и двойная нагрузка часто подрывает позицию женщин на рынке труда и ставит под угрозу их доступ к кредитам и другим производственным ресурсам. Это может заставить женщин искать неофициальную работу или работу на неполный рабочий день, для того, чтобы они могли совмещать работу с обязанностями по дому [5].

В целом, в более богатых странах, таких как Соединенные Штаты, как правило, расходуется меньшее количество времени на неоплачиваемый труд, чем более бедных странах, таких, например, как Мексика. В Японии недавно был начат ряд инициатив, увеличивающих число занятых на рынке труда женщин, так как лидеры страны осознали, какое это имеет значение для экономического роста.

По сравнению с женщинами, мужчины тратят большую часть времени на работу по дому в скандинавских странах, и меньшую часть времени в Индии, Мексике, Турции и Японии. В Норвегии, например, женщины тратят чуть более 3,5 часов в день на неоплачиваемую работу, а мужчины - три часа. В Индии женщины тратят шесть часов, а мужчины меньше часа. Без сравнения с женщинами, мужчины Южной Кореи 0,7 часа (рисунок 1). В Соединенных Штатах женщины тратят около четырех часов в день на неоплачиваемую работу, мужчины - около 2,5 часов.

Во всем мире женщины тратят в среднем 4,5 часа в день на неоплачиваемую работу, в том числе покупку продуктов, уход за детьми. Это в два раза больше, чем тратят мужчины, согласно данным Организации экономического сотрудничества и развития. Мужчины тратят значительно больше времени на оплачиваемую работу, а также на развлекательные мероприятия, которые включают в себя занятия спортом, телевидение и времяпрепровождение с друзьями.

Это гендерное неравенство начинается в детстве: американские девушки в возрасте от 10 до 17 лет тратят на домашние дела на два часа больше, чем мальчики еженедельно, и мальчики на $15 \%$ имеют больше шансов получить оплату за работу по дому, в соответствии с исследованиями Мичиганского университета [6]. 
В соответствии с данными Организации экономического сотрудничества и развития, если время, которое женщины тратят на неоплачиваемый труд сокращается с пяти до трех часов в день, то их участие как рабочей силы в оплачиваемом труде увеличивается на 20\%. Женщины могли бы выполнять больше оплачиваемой работы и получать более высокий уровень образования, если бы мужчины выполняли больше неоплачиваемой работы, или если бы и те, и другие выполняли домашней работы поровну.

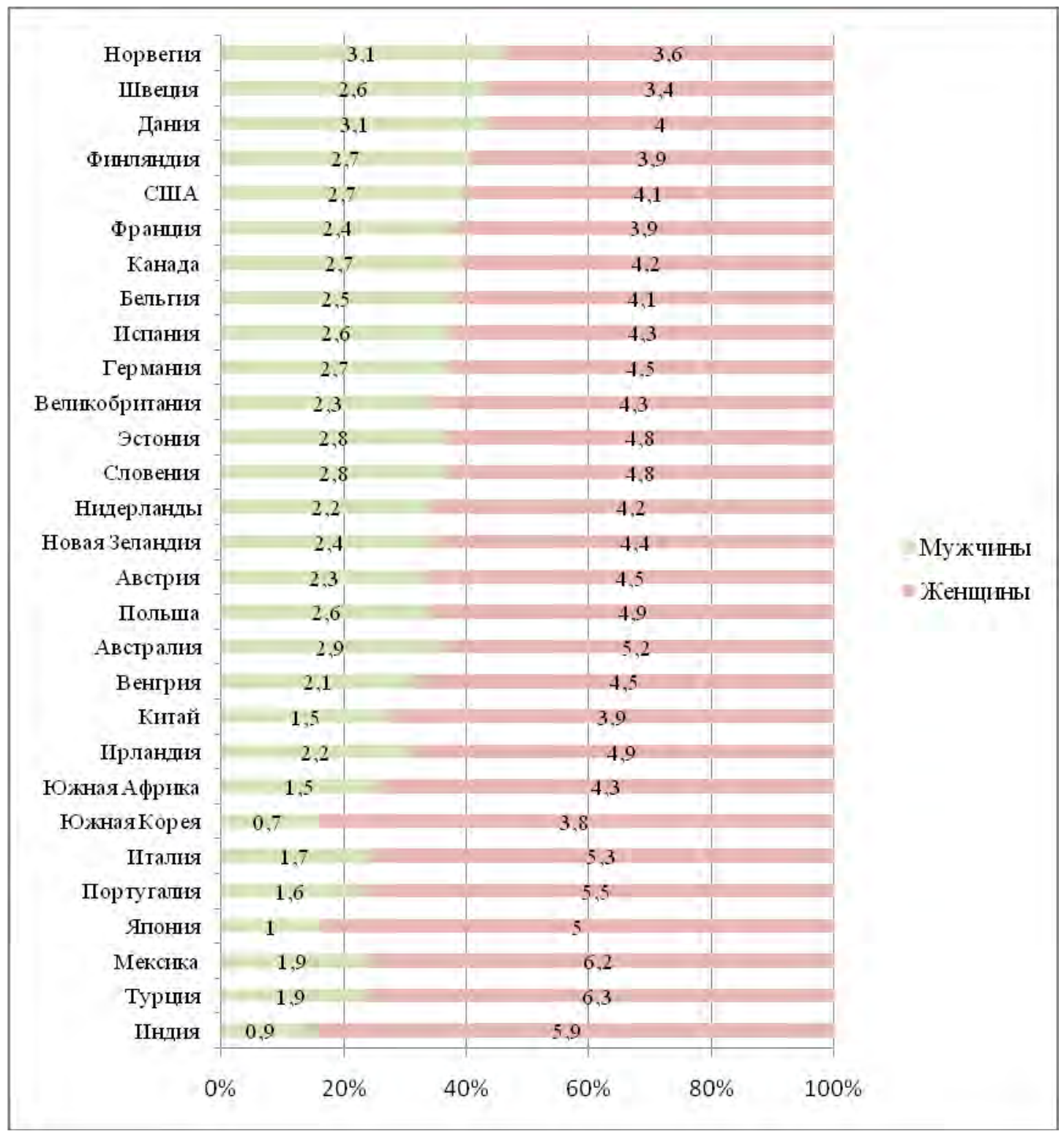

Рисунок 1 - Доля мужской и женской неоплаченной работы по дому в день в разных странах. Источник: [5].

Есть несколько способов, чтобы сократить время, затрачиваемое неоплачиваемый труд. Диана Элсон, социолог и экономист из 
Университета Эссекса в Великобритании и советник по вопросам женщин и развития Организации Объединенных Наций, утверждает, что неоплачиваемая работа должна быть признана, сокращена и перераспределена. Перераспределение неоплачиваемой работы «в пользу» мужчин может осуществляться посредством политической воли (например, оплачиваемый отпуск по семейным обстоятельствам) [6].

Несмотря на некоторые различия в разных регионах и странах, можно выявить тенденцию концентрации женщин в таких секторах экономики как сельское хозяйство, текстильная промышленность, производство одежды, продуктов питания, а также бытовых и социальных услуг («горизонтальная сегрегация по половому признаку»); также необходимо отметить, что женщины недостаточно представлены в органах власти и принятия решений («вертикальная сегрегация по половому признаку»). И наоборот, мужчины более равномерно распределены по более широкому кругу профессий [7].

По данным Международной Организация труда (МOT) женщины составляют большую долю «неоплачиваемых работников семейных предприятий» во всех регионах мира. Это гендерная разница особенно заметна в Южной Азии, где неоплачиваемая работа на семейном предприятии составляет $39 \%$ занятости женщин по сравнению с $11 \%$ мужчин, а также в странах Африки, где соответствующие цифры составляют 40\% женщин и 19\% мужчин [8]. «Неоплачиваемый работник семейного предприятия» является наиболее уязвимой формой занятости, так как его статус не подразумевает независимого доступа к доходам (рисунок 2).

Гендерное неравенство варьируется от одного уклада общества к другому и меняется с течением времени. Первым юридическим документом, который содержит комплексный подход к запрету дискриминации в отношении женщин, является Конвенция о ликвидации всех форм дискриминации в отношении женщин, которая была подписана правительствами в 1979 году, вступила в силу в 1981 году и в настоящее время подписана 187 государствами-участниками.

Пекинская декларация и Платформа действий были подписаны правительствами 189 стран в 1995 году. Декларация является первым международно-правовым документом, включающим подробный план действий, который устанавливает стратегии обеспечения равенства и полные права человека для женщин в 12 областях: бедность, образование и профессиональная подготовка, здравоохранение, насилие в отношении женщин, вооруженные конфликты, экономика, власть и принятие решений, институциональные механизмы для улучшения положения женщин, права человека, средства массовой информации, охрана окружающей среды. 
Гендерное неравенство можно рассматривать с нескольких позиций:

a) возможности (основные права человека, такие как знания и здоровье). Они имеют основополагающее значение для благополучия индивида и создают предпосылки для привлечения к оплачиваемой работе и принятия экономических решений. Они, как правило, измеряется с помощью различных показателей образования, здравоохранения и питания.

б) доступ к ресурсам и возможностям (условия, которые позволяют отдельным лицам зарабатывать адекватные средства к существованию, доступ к экономическим активам и ресурсам, а также участие в принятии решений). Доходы и занятость обычно используется в качестве меры доступа к экономическим ресурсам. Доля женщин в управленческих органах и органах власти является показателем политических возможностей.

в) безопасность (уязвимость по отношению к насилию и конфликтам). Насилие и конфликты вызывают физические и психологические травмы, подрывают способность отдельных лиц и общества в целом реализовать свой потенциал. Безопасность можно измерять с помощью таких показателей, как сексуальные домогательства или незаконный трафик женщин.

Гендерное неравенство может измеряться в абсолютных и относительных величинах. В относительном выражении, гендерное неравенство может быть оценено как соотношение мужчин и женщин, которое можно назвать Индексом гендерного паритета (GPI), который высчитывается по следующей формуле:

$$
G P I_{i}^{t}=\frac{F_{i}^{t}}{M_{i}^{t}},
$$

где $F_{i}^{t}$ и $M_{i}^{t}$ количество мужчин и женщин соответственно показателя $i$ во времени $t$.

Индекс гендерного паритета (GPI) как правило, используется для измерения относительной доступности образования для мужчин и женщин. Если индекс гендерного паритета равен 1, то это указывает на равное соотношение между мужчинами и женщинами, от 0 до 1 меньшее количество женщин [10, с.332].

Можно измерить относительный разрыв (Relative $\mathrm{Gap}_{\mathrm{i}}^{\mathrm{t}}$ ) как разницу между количеством мужчин и женщин определенного показателя (например, уровень грамотности, уровень занятости и т.д.), который выражается формулой

$$
\text { Relative Gap } \operatorname{pi}_{i}^{t}=\frac{M_{i}^{t}-F_{i}^{t}}{M_{i}^{t}} * 100,
$$

где $F_{i}^{t}$ и $M_{i}^{t}$ определены, как указано выше. Относительный разрыв также может быть измерен с точки зрения заработной платы, и в данном 
случае это называют гендерным разрывом в оплате труда (или разрыв в оплате труда) [10, с.332].

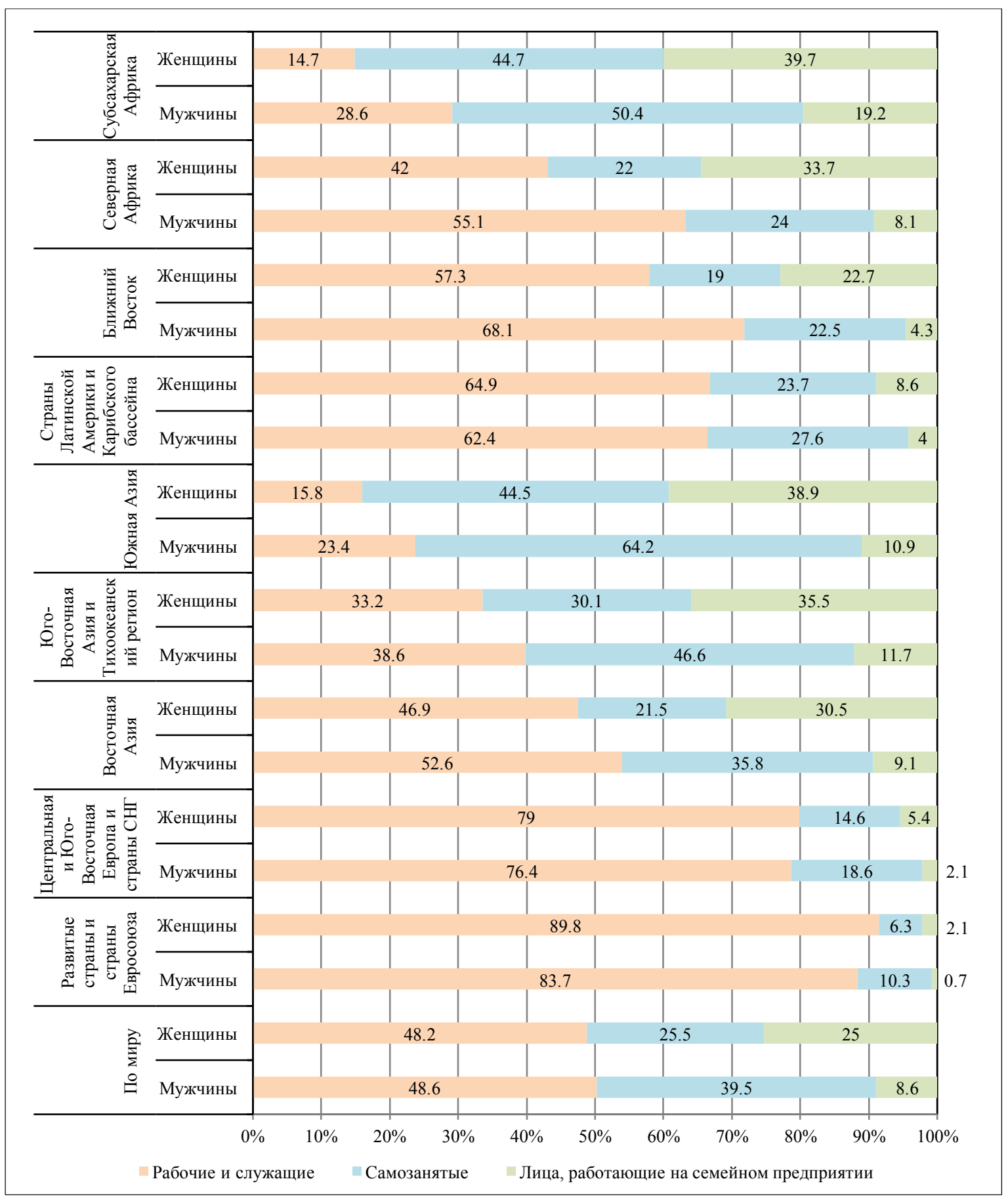

Рисунок 2 - Международное распределение общей занятости по статусу и полу, 2012 (\%).Источник: [9]

Гендерный разрыв в заработной плате является относительным показателем гендерного неравенства в доходах. Этот показатель отражает разницу между средней заработной платой мужчин и женщин, которая выражается в процентах от средней заработной платы мужчин. 
В формуле (2), показатель $i$ означает среднюю заработную плату. В этом смысле гендерный разрыв в заработной плате указывает на то, в каком положении оказываются женщины с точки зрения среднего заработка мужчин. Например, гендерный разрыв в заработной плате в 30 \% указывает на то, что женщины зарабатывают на 30\% меньше, чем мужчины, и, таким образом, оказываются в «положении недостатка»; разрыв в оплате труда мужчин в 10\% предполагает, что женщины зарабатывают на 10\% больше, чем мужчины, и таким образом, женщины оказываются в «положении преимущества».

Многочисленные исследования показали, что не смотря на прогресс, ни в одной стране мира не было преодолено гендерное неравенство: «гендерное неравенство в области базовых прав устойчиво сохраняется во всех регионах» [11, с. 5].

К сожалению, рассмотренные выше проблемы гендерного неравенства актуальны и для Республики Беларусь. Хотя были подписаны и ратифицированы основные документы ООН, направленные на защиту интересов женщин и достижение гендерного равенства, и Беларусь на международном уровне взяла на себя конкретные обязательства по выполнению Конвенции о ликвидации всех форм дискриминации в отношении женщин (CEDAW), в том числе подписала Дополнительный Протокол к ней, а также Декларацию IV Всемирной Конференции по улучшению положения женщин (Пекин, 1995г.), Декларацию тысячелетия, проблема достижения гендерного равенства требует внимания и больших усилий не только со стороны органов управления, но и со стороны общества в целом.

Международные обязательства Беларуси подразумевают, что государство должно определить гендерное равенство одним из своих приоритетов и сформировать национальную гендерную политику. В 2000 году был создан Национальный Совет по гендерной политике при Совете Министров Республики Беларусь. Членами Национального Совета стали представители различных министерств и ведомств, а также представители трех женских общественных объединений - Белорусского Союза женщин, Женского независимого демократического движения и Белоруской ассоциации молодых христианских женщин.

Однако на законодательном уровне осталась нерешенной проблема насилия в отношении женщин, в том числе не принят закон «О противодействии домашнему насилию», правовые акты в отношении сексуального домогательства, о возмещении морального и финансового ущерба жертвам, о решении жилищной проблемы. Не включен на рассмотрение белорусского парламента проект закона «О гендерном равенстве». 
Эксперты в гендерной сфере называют три главные проблемы белорусских женщин - неравноправие на рынке труда, домашнее насилие, сексуальные домогательства на работе.

Эксперты отмечают сохранение и обострение проблем женщин на рынке труда, таких как: феминизация неперспективных, не престижных и мало оплачиваемых сфер деятельности, вытеснение женщин с управленческих позиций; ухудшение условий труда женщин.

Нормы белорусского законодательства, в целом гендерно нейтральные, не содержат дискриминационных положений в отношении женщин и их трудовых прав. Вместе с тем гарантии, закрепленные в законодательных актах, реализуются далеко не в полной мере. На практике существует разница между юридическим и фактическим равноправием. Причины этой проблемы заключаются в первую очередь в отсутствии эффективных законодательных и институциональных механизмов, направленных на установление гендерного равенства, а также в наличии в общественном сознании патриархальных гендерных стереотипов.

Белорусская политика по обеспечению равенства полов должна базироваться на антидискриминационных законодательных актах, так как именно правовая база обеспечивает необходимую основу для развития равенства и служит предохранительной мерой против практики дискриминации по половому признаку, в частности, на рынке труда. Существующее трудовое законодательство по своей сути основано на защитной идеологии по отношению к женщине, оно не способствует повышению конкурентоспособности женщин на рынке труда, трудновыполнимо на практике, так как в нем отсутствуют механизмы привлечения к ответственности за дискриминационные действия в отношении женщин. И как итог: в Беларуси «средняя заработная плата женщин составляет около $76 \%$ средней заработной платы мужчин» $[12$, с. 6]. На уровне законодательства осталась не решенной проблема насилия в отношении женщин: отсутствует упрощенная процедура оформления фактов насилия, снятия побоев, правовые механизмы по изоляции насильника от своих жертв, неадекватны правовые акты о сексуальном домогательстве, о возмещении ущерба - морального и финансового, о разрешении жилищной проблемы.

Согласно Докладу о человеческом развитии 2015 года, Беларусь входит в 16 стран мира, где индекс человеческого развития женщин равен или превосходит аналогичный показатель среди мужчин. По индексу гендерного неравенства наша республика занимает 50-е место среди 188 стран мира. Существенный вклад в индекс человеческого развития женщин вносит их высокий образовательный уровень, который сохраняется длительное время. Так, численность обучающихся 
в учреждениях высшего образования женщин в 2014/2015 учебном году составляет 56,9\% от числа мужчин. Среди занятых в экономике доля работающих женщин с высшим образованием составляет $33,9 \%$, в то время как аналогичный показатель среди мужчин - 24,4\%. Среди профессорскопреподавательского состава вузов - 55,7\% женщин. Согласно страновому анализу Рамочной программы ООН в Беларуси, достигнут высокий показатель средней продолжительности обучения - 11,5 лет и один из самых высоких показателей ожидаемой продолжительности обучения $(15,7$ лет) среди 28 стран Центральной и Восточной Европы и постсоветских стран. За последние 10 лет продолжительность жизни в Республике Беларусь в целом увеличилась на 4,1 года. Но вызывает тревогу большой гендерный разрыв этого показателя. Статистика показывает, что уровень смертности мужчин в трудоспособном возрасте более чем в 4 раза превышает уровень смертности женщин, в том числе за счет внешних причин.

В фокусе внимания находятся вопросы обеспечения занятости женщин, оказания им социальной поддержки на период поиска работы, профобучения и развития предпринимательства. На протяжении многих лет женская безработица в Беларуси преобладала, как и в большинстве стран мира. Благодаря реализации целенаправленных мер на государственном и региональном уровне гендерный фактор безработицы минимизирован: удельный вес женщин среди безработных постоянно снижается. По статистике, на конец 2014 года на учете в органах по труду, занятости и социальной защите в качестве безработных состояли 24,2 тыс. человек, из них 9,1 тыс. женщин, или 37,6\% (для сравнения: на конец 2011 года женщин среди безработных было 54,1\%).

Как следствие принимаемых мер на рынке труда республики наблюдается смягчение ситуации с женской безработицей. Так если на конец 2005 года доля безработных женщин в общей численности безработных составляла 69\%, то уже в начале 2016 года - 32\% [12, с. 6]. В целом женщины составляют более половины общей численности членов общественных объединений, действует 30 женских общественных объединений. За последние пять лет возросла роль женщин на уровне принятия решений. Женщины - государственные служащие всех уровней управления составляют $68,5 \%$, в том числе на должностях руководителя организации или его заместителей - 52,9. Однако интенсивная занятость и высокий образовательный уровень женщин совершенно не обеспечивает им какое-то равенство в доходах, так как занятость женщин преобладает в бюджетных отраслях. Яркий пример: в сфере здравоохранения, образования и культуры работает до 80\% женщин с заработной платой на 20\% меньшей, чем у мужчин. Но, если мы посмотрим сферы, где 
зарплаты более высокие, то разница между доходом женщины и мужчины в среднем составляет уже $30 \%$.

Достижение гендерного равенства не возможно без постоянной исследовательской и образовательной работы. Лица, принимающие решения, должны понимать сущность гендерных отношений.

Для продвижения политики гендерного равенства необходимо участие женщин в политической и общественной жизни, а также в процессах принятия решений и на всех уровнях. Международный опыт показывает, что в странах, где значительное число женщин принимают участие в принятии решений, изменения в области гендерного равенства происходят быстрее и являются более значительными. Необходимо вовлечение женщин в политическую и общественную деятельность, увеличение их количества в руководящих органах. Необходимо соблюдать гендерный баланс руководства, следует добиваться, чтобы в органах власти было представлено не более 60 процентов представителей одного пола.

В продвижении и реализации политики гендерного равенства большую роль играют женские общественные организации. Деятельность женских организаций включает исследования и мониторинг проблем женской социальной группы, различные образовательные программы и консультационные услуги для женщин, попавших в кризисные ситуации.

Национальный план действий по обеспечению гендерного равенства в Республике Беларусь на 2011-2015 годы - является основополагающим документом, направленным на обеспечение условий равного участия мужчин и женщин во всех сферах жизнедеятельности. Среди задач, обозначенных в документе - содействие достижению паритетного представительства мужчин и женщин на всех уровнях управления; внедрение «гендерных знаний» в систему образования, формирование в общественном сознании необходимости социального равенства мужчин и женщин во всех сферах общественной жизни. Речь идет также о сохранении и укреплении репродуктивного здоровья мужчин, женщин и подростков для обеспечения нормального воспроизводства населения и повышения качества жизни. Особое внимание уделено укреплению института семьи и семейно-брачных отношений, пропаганде ценностей брака и семьи, достижению гендерного равенства в семейных отношениях, в том числе вовлечению мужчин в сферу домашнего труда и процесс воспитания детей. Ярким примером является опыт Швеции, где 1 июня 2008 года был введен «бонус» - 13500 крон получают семьи, в которых отпуск по уходу за ребенком делят поровну оба родителя. Это пример «намерения Правительства усилить равномерность распределения ответственности за детьми между родителями... стимулировать равномерное распределение отпуска по уходу 
за ребенком между женщинами и мужчинами, что создает условия для достижения материального равенства» [13, с. 34].

Важным является содействие достижению гендерного равенства в экономической сфере, дальнейшее развитие предпринимательства среди женщин, повышение конкурентоспособности женщин на рынке труда. Акцент сделан на трансформации общественного сознания, искоренении гендерных стереотипов, связанных с идеей превосходства и доминирования одного пола над другим. В настоящее время ведется работа по созданию Национального плана действий по достижению гендерного равенства в Республике Беларусь на 2016-2020 годы. Проект позволил привлечь не только финансовую, но и экспертную поддержку ведущих научных учреждений России, в том числе и по гендерным вопросам.

\section{ВЫВОДЫ}

Гендерный подход играет важную роль и обеспечивает основу для переосмысления основ экономической и торговой политики. Экономика должна рассматриваться как «гендерная структура», т.е. часть системы общественных отношений, в которые уже включен гендер. Рассматривая экономику как гендерную структуру, следует сделать акцент на неоплачиваемой работе по дому и уходу за членами семьи, что имеет жизненноважное значение для дальнейшего функционирования рыночноориентированной экономики. Поэтому необходимо расширить границы экономической системы, которая должна включать как рыночные, так и нерыночные направления деятельности.

Несмотря на некоторые различия в разных регионах и странах, можно выявить тенденцию концентрации женщин в таких секторах экономики как сельское хозяйство, текстильная промышленность, производство одежды, продуктов питания, а также бытовых и социальных услуг.

Первым юридическим документом, который содержит комплексный подход к запрету дискриминации в отношении женщин, является Конвенция о ликвидации всех форм дискриминации в отношении женщин, которая была подписана правительствами в 1979 году, вступила в силу в 1981 году и в настоящее время подписана 187 государствамиучастниками.

Проблемы гендерного неравенства актуальны и для Республики Беларусь. Основными проблемами белорусских женщин являются отсутствие равноправия на рынке труда, домашнее насилие, сексуальные домогательства на работе. 
Многочисленные исследования показали, что, не смотря на прогресс, ни в одной стране мира не было преодолено гендерное неравенство. Решением гендерного неравенства может стать в первую очередь признание неоплачиваемой работы, которая должна быть сокращена и перераспределена. Перераспределение неоплачиваемой работы «в пользу» мужчин может осуществляться посредством политической воли (например, оплачиваемый отпуск по семейным обстоятельствам).

\section{ЛИТЕРАТУРА}

1. Гендерные проблемы и развитие. Стимулирование развития через гендерное равенство в правах, в доступности ресурсов и возможности выражать свои интересы / Пер. с англ. - М: Издательство «Весь Мир», 2001. - $408 \mathrm{c}$.

2. Trade and Gender United Nations Conference on Trade and Development / United Nations New York and Geneva, 2014. - 102 p.

3. Ниеманис, А. Практическое руководство по внедрению гендерных подходов / А. Ниеманис. - Братислава, 2005. - 36 с.

4. Gender and indigenous peoples' economic and social development [Electronic resource]. - 2007. - Mode of Access: http://www.un.org/ womenwatch/ osagi/concepstandefinitions.html - Date of Access: 02.03. 2016.

5. Rasavi, S. Gender and Social Policy in Global Context: Uncovering the Gendered Stcucture of "the Social" / Shahra Rasavi, Shireen Hassim. UNRISD: Palgrave, Basingstoke, 2006.

6. Miller, C. How Society Pays When Women's Work Is Unpaid / C. Miller [Electronic resource]. - 2016. - Mode of access: http://www. nytimes. com/2016/02/23/upshot/how-society-pays-when -womens- work- isunpaid. html - Date of access: 12.04.2016.

7. Antonopolous, R. The unpaid care work - paid work connection. [Electronic resource]. - Mode of access: http:/www.ilo.org/wcmsp5/groups/ public/ ---dgreports/ - integration/documents/ publication/ wcms_119142. Date of access: - 17.04.2016.

8. Rasavi, S. The Social and Political Economy of Care: Contesting Gender and Class Inequalities/ S. Rasavi, S. Staab. - EGM/ESOR/2008/BP.3. Division for the advancement of Women, Department of Social and Economic Affairs. United Nations, New York, 2008.

9. World Development Report: Gender Equality and Development. Chapter 5. World Bank, Washington DC,World Bank, 2012.

10. Investing in cultural diversity and intercultural dialogue: UNESCO world report. [Electronic resource]. - Mode of access: http://unesdoc.unesco. org/ulis/cgi-bin/ulis.pl?catno $=185202 \& \mathrm{gp}=1 \& \operatorname{mode}=\mathrm{e} \&$ lin $=1-$ Date of access: -20.04 .2016 . 
11. Мезенцева, Е. Гендерное измерение в программах социальноэкономического развития: эволюция методологических подходов и целевых критериев / Е. Мезенцева. - Москва: Working Papers/2012-1 Серия: Методология гендерных исследований, 2012. - 35 с.

12. Совершенствование гендерной статистики для принятия решений. Доклад. - Минск, Национальный статистический комитет Республики Беларусь: 2016.

13. Гендерное равноправие. Ответственность всего Правительства // Министерство иностранных дел Швеции. - Блумквист, 2014. - 54 с.

Статья поступила в редакиию 10 ноября 2016 года. 